\title{
Travelling Energy Collectors
}

\author{
Ernst Kussul*, Tatiana Baidyk, José Saniger, Felipe Lara, Neil Bruce \\ CCADET, UNAM, Mexico city, Mexico \\ * Corresponding author. Tel: +52 5556228602 ext.1204, Fax: +52 55 55500654, E-mail: \\ ekussul@servidor.unam.mx
}

\begin{abstract}
Almost all modern solar and wind energy plants can be used only as auxiliary energy sources because of their intermittent character. On the other hand, geothermal systems can produce energy continuously. However, geothermal power plants need expensive wells, and the well will not always give high temperature underground water. It is possible to improve the performance of the plant by combining the different features of these mentioned systems. It is possible to obtain hot water not from drills but by using solar and wind energy installations placed on mobile platforms (travelling energy collectors) that will transport hot water to the power plant, where it will be stored in special tanks. A similar procedure is possible for cold water. To transform thermal energy, stored in the hot water and cold water tanks to electric energy it is possible to use conventional equipment of geothermal power plants. In this paper we give estimations of some parameters of the proposed power generation system based on travelling energy collectors. The estimations show that the power plant based on travelling energy collectors can be considered as a base load source of electric energy.
\end{abstract}

Keywords: Solar energy, Wind energy, Travelling energy collector

\section{Introduction}

Solar energy and wind energy can be considered as complementary. Solar energy can be captured only during daytime. Wind energy at a height of more than 80 meters is more intensive at night time. In summer it is possible to obtain more solar energy than in winter, and in winter there is more wind energy. So, it is useful to make power plants based on both solar and wind energies.

If we want to create a base load power plant that uses solar and wind energy we also need to store energy for at least some days. The best type of energy storage for such a period is Thermal Energy Storage (TES). Many types of thermal energy storages have been proposed. In this article we will suppose that the TES is based on hot and cold water. Water is the cheapest material and it has high heat capacity.

The proposed solar-wind power plant will work as follows: solar concentrators will prepare hot water for TES, and wind powered refrigerators will produce cold water for TES. Sometimes wind powered heaters can be added to produce an additional amount of hot water. Hot water and cold water from the TES will be used to produce the electric energy with the same equipment that is used for geothermal power plants. The hot water from the TES can also be used for space heating and the cold water can be used for air conditioning purposes.

In principle, the solar concentrators can be placed in a compact area, but the wind power installations must be distributed in a relatively large region because of the turbulences that each installation produces. Moreover, wind speed is higher over the sea surface, and the power plant is to be located on the shore. For these reasons we propose Travelling Energy Collectors (TEC) that will collect solar and wind energy on the sea surface and transport this energy in the form of hot and cold water to the power plant. The distance of transportation (or service radius) will depend on economical considerations and can vary from some kilometers to many tenths of kilometers. 


\section{Methodology}

\subsection{Power plant based on travelling energy collectors}

The scheme of the power plant based on travelling energy collectors (TEC power plant) is shown in Fig.1.

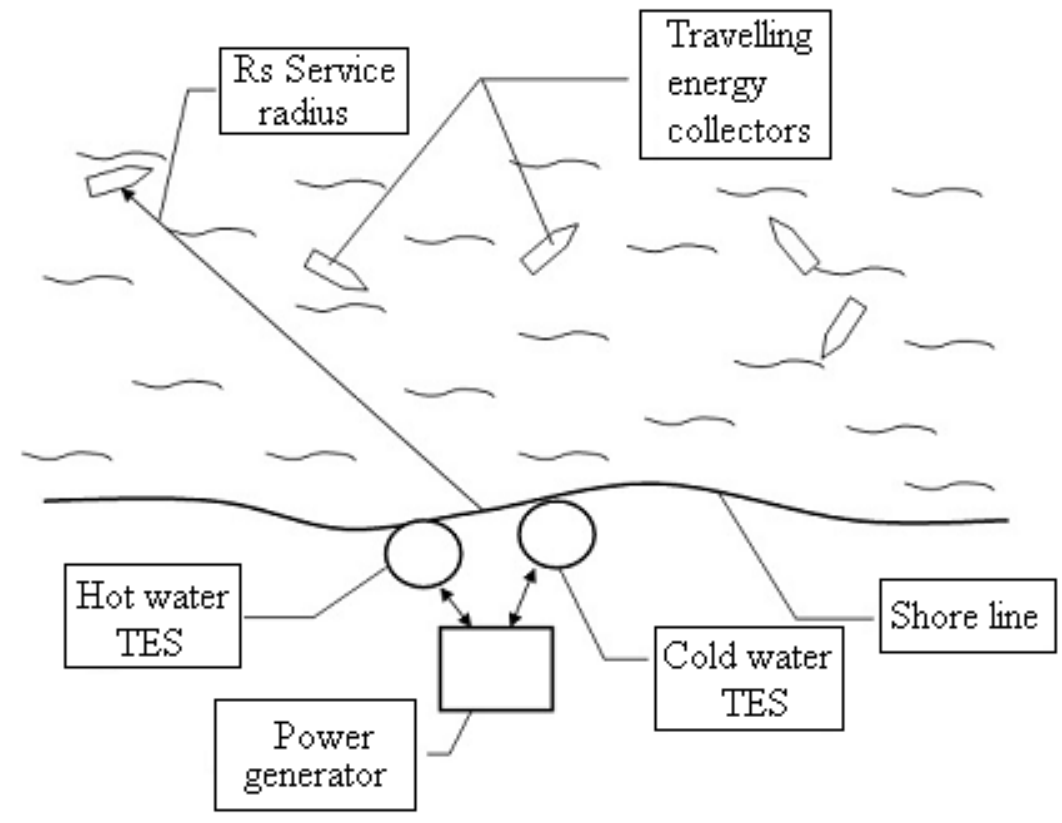

Fig. 1.Power plant based on travelling energy collectors.

It contains a power generator, hot water TES, cold water TES, and a multitude of thermal energy collectors (TECs). The TECs collect the solar and wind energy from the circular segment that has radius $R_{S}$, transform these energies to the hot water and cold water, and transport them to the hot water TES and cold water TES. The water from the hot water TES is supplied to the vapor generator that produces energy in the heat engine with the Organic Rankine Cycle (ORC). This type of engine is used for geothermal power plants. The water from the cold water TES is used for heat engine cooling. The Carnot efficiency of the power generator will be:

$\eta_{c}=\left(T_{h}-T_{c}\right) / T_{h}$

where $T_{h}$ is the temperature of hot water and $T_{c}$ is the temperature of cold water. The total efficiency of the power generator will be:

$\eta=\eta_{c} \cdot \eta_{r}$

where $\eta_{r}$ is the relation of power generator efficiency to its Carnot efficiency. For ORC heat engines $\eta_{r}$ usually has the values in the range of $0.5-0.67$ [1]. In this article we will use a value $\eta_{r}=0.55$

If the temperature of the hot water is $90^{\circ} \mathrm{C}$ and the temperature of the cold water is $5^{\circ} \mathrm{C}$, the efficiencies of the power generator will be:

$\eta_{c}=0.234, \quad \eta=0.129$ 
If we put the hot water TES at a depth of $50 \mathrm{~m}$ below the sea surface to obtain overpressure of 5 bar, it will be possible to increase the hot water temperature up to $140^{\circ} \mathrm{C}$. The temperature of the cold water can be decreased down to $-20^{\circ} \mathrm{C}$, if we use an ice-water mixture of salted water. In this case the power generator efficiencies will be:

$\eta_{c}=0.387, \quad \eta=0.21$

The efficiency 0.21 is at the level of the highest efficiencies of silicon photovoltaic panels, but in our case the power generator can supply the energy continuously.

\subsection{Travelling energy collectors}

A travelling energy collector (TEC) will be made as an unmanned sail catamaran. The scheme of the TEC is presented in Fig.2.

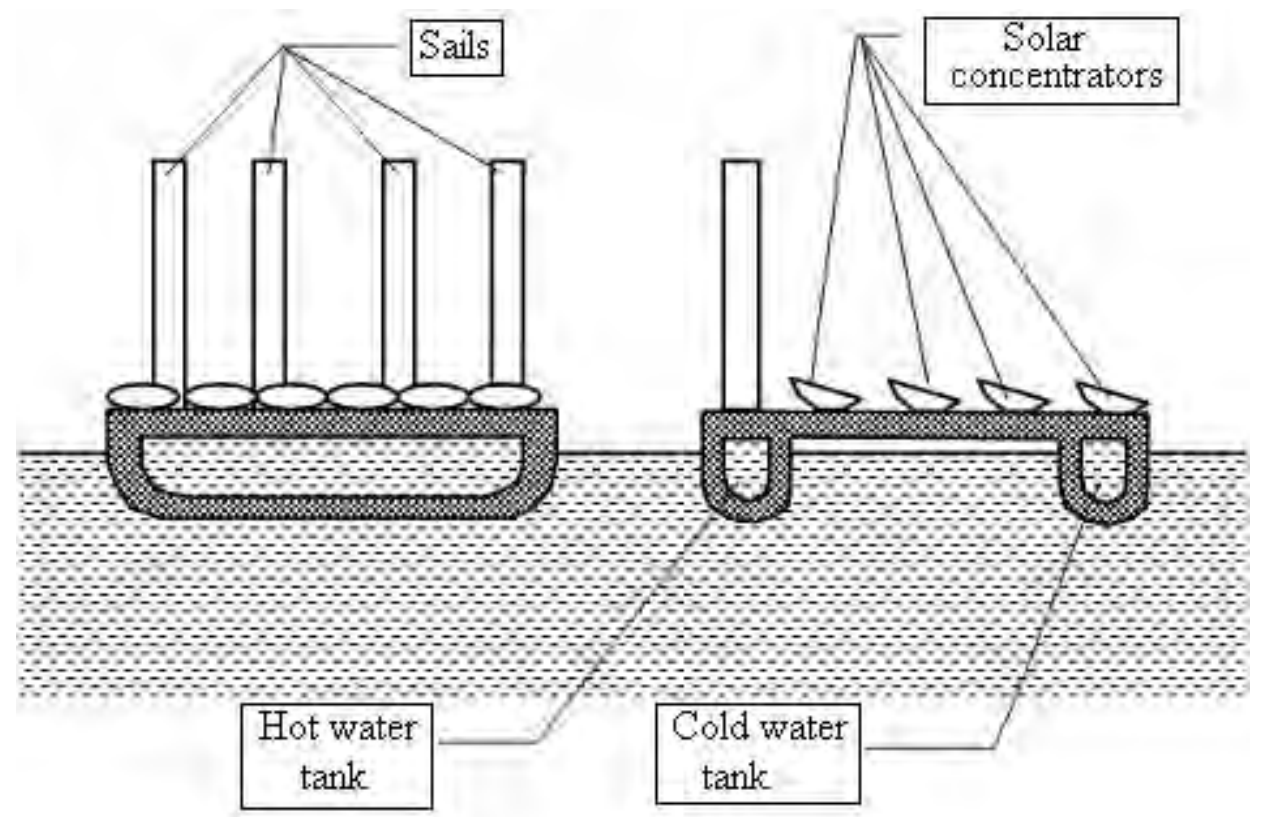

Fig.2. The scheme of the TEC.

The TEC contains sails, solar concentrators, small wind turbines, hot water tank and cold water tank. There are different types of maritime wind collectors. Some of them contain large wind turbines on the ship, others use the sails to move the ship, and submerged water turbine produce the electric energy [2].We propose to use small wind turbines, because large wind turbines have large weight, and the scheme containing the submerged water turbine has low efficiency. Small wind turbines can be placed into the sails (Fig.3).

In this case the film roll and the rope roll will be placed in the leading edge of the sail. When the TEC is working in the mode of wind energy collection, the sail film is wound to the film roll and small wind turbines are open for the wind. If the sail is to be used to move the catamaran, the ropes will be wound to the rope roll. These ropes run around the rear roll and pull the film from the film roll to close the wind turbine space and to form the sail air foil. The TEC will work in solar energy mode in the presence of direct solar radiation; otherwise it will work in wind energy mode, in transport mode, or in discharge mode. 


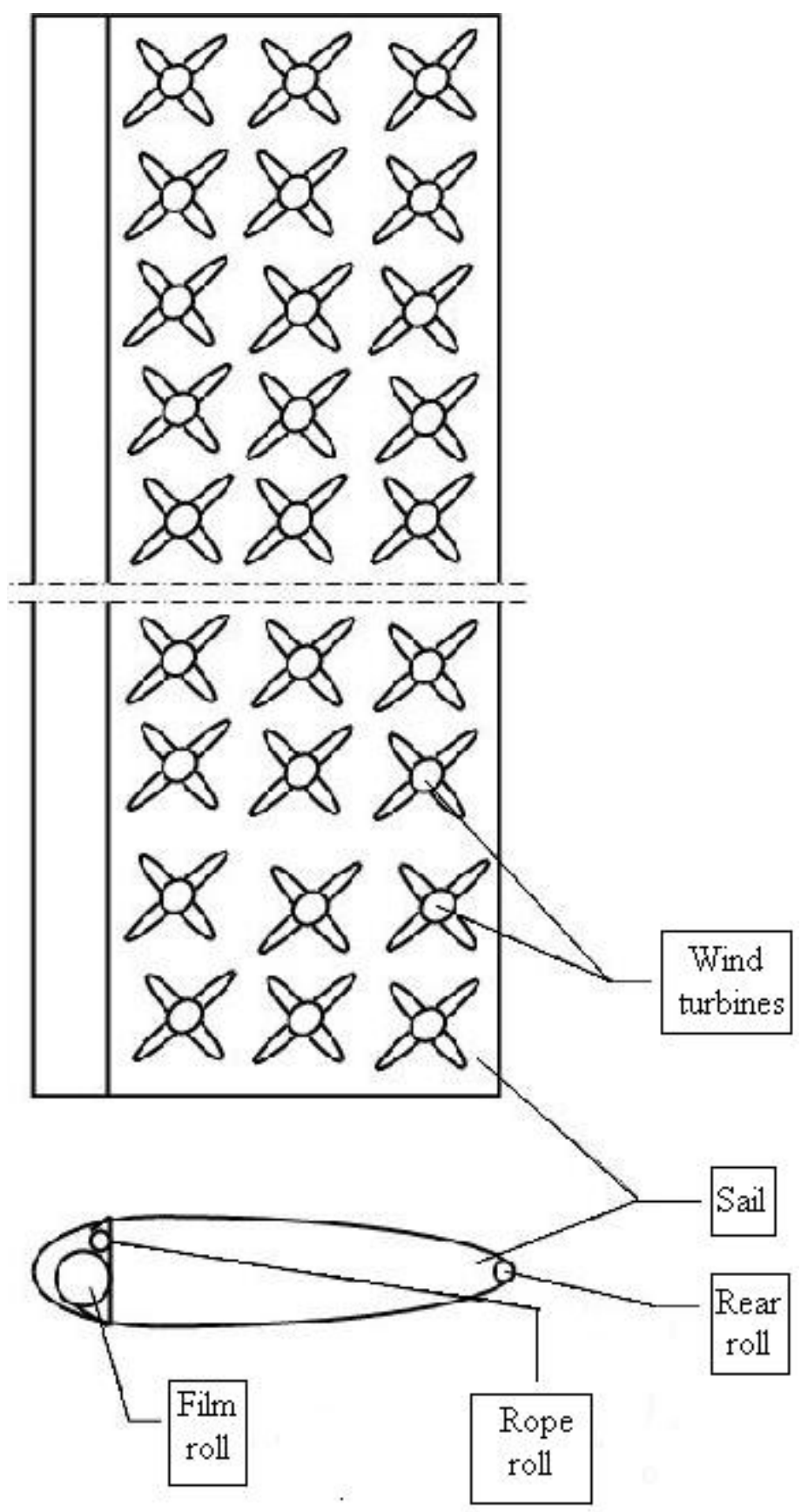

Fig.3. Small wind turbines.

In the solar energy mode the solar collectors will heat the water in the hot water tank. In the wind energy mode the energy from the wind turbines will feed the chiller to cool the ice-water mixture in the cold water tank and increase the amount of ice in the mixture. The approximate proportion of hot water energy to the cold water energy is:

$$
E_{h} / E_{c}=T_{h} / T_{c}
$$

where $E_{h}$ is the energy of the hot water stored in the hot water tank, $E_{c}$ is the energy of the ice-water mixture stored in the cold water tank, $T_{h}$ is mean temperature of the hot water tank, and $T_{c}$ is the temperature of the cold water tank. 
The hot-water energy can be calculated using the equation:

$$
E_{h}=M_{h} \cdot C_{w} \cdot\left(T_{h 1}-T_{h 2}\right) \text {, }
$$

where $E_{h}$ is the hot water energy, $M_{h}$ is the hot water mass, $C_{w}$ is specific heat capacity of the water, $T_{h 1}$ is the temperature of the hot water after the heating in the solar concentrators, $T_{h 2}$ is the temperature of the hot water before heating in the solar concentrators.

To calculate the cold water energy we will use the following equation:

$$
E_{c}=M_{i} \cdot q_{i},
$$

where $E_{c}$ is the cold water energy, $M_{i}$ is the mass of the ice in the ice-water mixture, and $q_{i}$ is the latent heat of ice melting.

\section{Solar Concentrators}

Low-cost light-weight solar concentrators are needed for travelling energy collectors to heat the water in the hot water tank. At present we are developing these concentrators [3]. Each concentrator will contain a multitude of flat triangular mirrors that approximate a parabolic surface. A prototype of the support frame for the mirrors is shown in Fig.4.

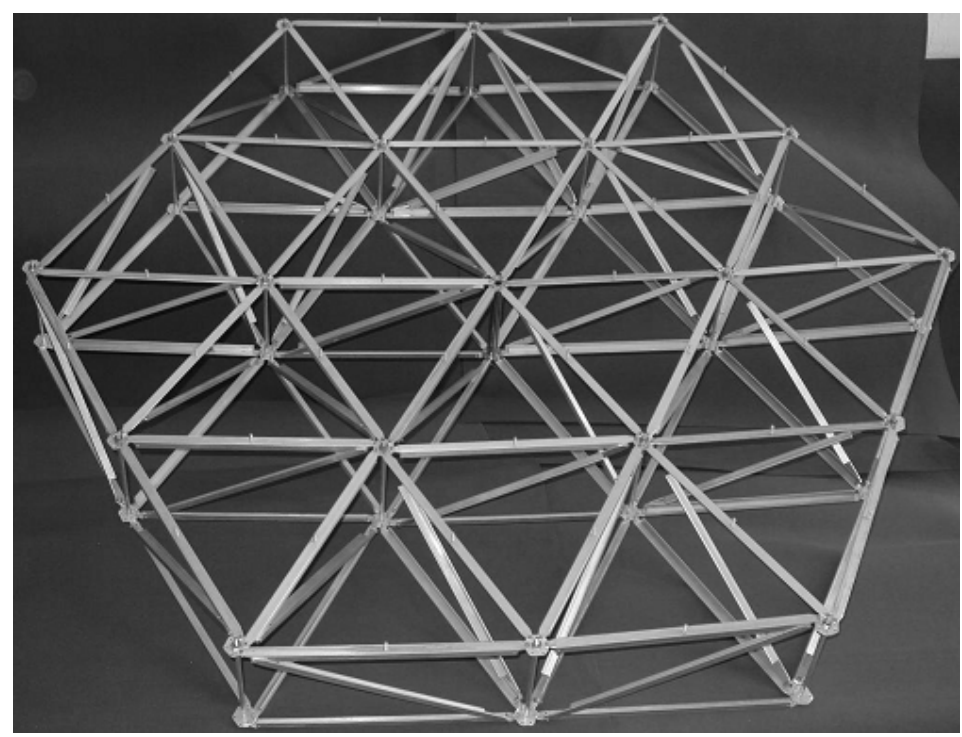

Fig.4. Support frame for the mirrors of solar concentrator.

The cost of mass production of these concentrators can be as low as 50 dollars for square meter of mirror surface [4].

\subsection{Solar energy mode}

The travelling energy collector will work in the solar energy mode in the presence of direct solar radiation. Let the TEC have a deck area of $1000 \mathrm{~m}^{2}$. In this case the total area of solar concentrators can be approximately $500 \mathrm{~m}^{2}$. Let us suppose that $1 \mathrm{~m}^{2}$ of solar concentrator produces $700 \mathrm{Wt}$ of heating power (concentrator efficiency is 0.7 ), and direct solar radiation is present during 4 hours per day. In this case the hot water will obtain the energy of 
$E_{h}=504 \cdot 10^{7} \mathrm{~J} /$ day.

Let the initial temperature of hot water be $T_{h 2}=403^{\circ} \mathrm{K}$, the final temperature of hot water will be $T_{h 1}=423^{\circ} \mathrm{K}$. In this paper we will consider a TEC that discharges the hot and cold water each day. Using equation (6) it is possible to calculate the mass of hot water needed to store the heat energy in the hot water tank. In our case we will have:

$M_{h}=60000 \mathrm{~kg}=60 \mathrm{ton}$,

\subsection{Wind mode}

In the nights and during cloudy days the TEC will work in the wind mode. For this purpose the TEC is to be oriented perpendicular to the wind speed, the sails are to be opened, and small wind turbines will produce the electrical energy for the ice machine. The ice machine will increase the amount of ice in the cold water tank. Using equations (5) and (8) we obtain:

$E_{c}=E_{h} \cdot\left(T_{c} / T_{h}\right)=504 \cdot 10^{7} \cdot(253 / 413)=308 \cdot 10^{7} \mathrm{~J} /$ day

Here we suppose that $T_{c}$ equals $-20^{\circ} \mathrm{C}$ and $T_{h}$ equals $140^{\circ} \mathrm{C}$.

The power of wind turbines can be evaluated using the equation:

$P_{t}=\eta_{t} \cdot S_{t} \cdot\left(\rho \cdot u^{3}\right) / 2$

where $\eta_{t}$ is turbine efficiency, $S_{t}$ is the total area of the small wind turbines, $\rho$ is the air density, and $u$ is the wind speed. In this paper we will assume that $\eta_{t}=0.3, S_{t}=500 \mathrm{~m}^{2}, \rho=$ $1.25 \mathrm{~kg} / \mathrm{m}^{3}$ and $u=8 \mathrm{~m} / \mathrm{s}$. In this case we will have:

$P_{t}=48000 \mathrm{Wt}$,

We will suppose that the transport and the discharge modes will take 3 hours per day. The solar mode takes 4 hours per day, so the wind mode will take 17 hours per day. Not all this time will be used for power generation, because the TEC has a drift that must be periodically compensated. For drift compensation the sails are to be closed as for transport mode and the TEC is to be moved against the wind. We will assume that drift compensation will take 30\% of the total time in the wind mode. The power generation in the wind mode will take $t_{g}=11.9$ hours per day. The energy generated by the wind turbines will be:

$E_{t}=P_{t} \cdot t_{g} \cdot 3600=206 \cdot 10^{7} \mathrm{~J} /$ day,

If coefficient of performance of the ice machine is 1.5, the total cooling energy produced in the form of ice will be $E_{c}=308 * 10^{7} \mathrm{~J} /$ day. This is sufficient to obtain the balance of heating and cooling energies in the power plant. To store this amount of energy it is necessary to produce the following mass of ice:

$M_{i}=E_{c} / q_{i}$, 
where $E_{c}$ is the cooling energy, $q_{i}$ is the latent heat of water freezing. Water has the value of $q_{i}=332 \mathrm{~kJ} / \mathrm{kg}$. For our example $M_{i}$ will be:

$M_{i}=9300 \mathrm{~kg}$.

We will assume that the mass of the ice-water mixture is:

$M_{\text {iw }}=40000 \mathrm{~kg}=40 \mathrm{ton}$,

In this case the total weight of hot water and cold water in the tanks will be 100 ton.

Different geographic areas have different relations between the amount of solar and wind energy, thus for each area different parameters of the power plant should be selected. The main parameter is the cold-water tank temperature. Increasing this temperature, it is possible to decrease the amount of wind energy to obtain good balance for example in tropical areas, where the wind energy can be relatively poor.

\subsection{Transport and discharge modes}

In transport mode the sails move the TEC from the power plant and after collection of energy return it to the power plant. The maximum distance of movement is:

$R_{s}=t_{t r} \cdot u_{t r} / 2$,

where $R_{s}$ is the service radius of the power plant, $t_{t r}$ is the time of the transportation mode, $u_{t r}$ is the transportation speed. In our example $t_{t r}=2$ hours. If the transportation speed is $10 \mathrm{~km} / \mathrm{h}$, the service radius will be:

$R_{\mathrm{s}}=10 \mathrm{~km}$.

In the discharge mode the TEC discharges the hot water to the large hot-water tank of the power plant. The temperature of the discharged water is $T_{h 1}$. After this the TEC loads its hot water tank from the large hot-water tank of the power plant with water that has the temperature $T_{h 2}$. In parallel the ice-water mixture that contains $M_{i 1}$ kilograms of ice is discharged to the large cold-water tank of the power plant and a new ice-water mixture that contains $M_{i 2}$ kilograms of the ice is loaded to the small cold-water tank of the TEC.

\subsection{TEC number}

One TEC produces the energy of $504 * 10^{7} \mathrm{~J} /$ day. This corresponds to a mean power $P_{T E C}=$ $58330 \mathrm{Wt}$. If we want to create a power plant of power $P_{p p}$, we need the following number $N_{\text {TEC }}$ :

$N_{T E C}=P_{p p} /\left(P_{T E C} \cdot \eta\right)$,

where $P_{p p}$ is the output power of the power plant, $P_{\text {TEC }}$ is the power of one TEC, $\eta$ is the efficiency of the power plant. If $P_{p p}=10 \mathrm{MWt}, \eta=0,21$, we need: 
$N_{\text {TEC }}=816$.

This calculation shows that each TEC cannot be driven by an operator. It must be made as an autonomous robot, and its cost is to be as low as possible.

\section{Discussion}

A power plant for continuous electrical energy supply is proposed. In this power plant the conventional equipment from geothermal power plants is used for electricity generation. Instead of drilling deep wells to obtain hot water we propose the use of moving platforms (TECs) that contain solar concentrators for hot water production and small wind turbines for cold water production. Moving platforms transport the hot and cold water to the power plant located on the sea shore. Approximate calculations show the feasibility of this system.

\section{Conclusion}

Travelling energy collectors will permit solar and wind energy collection from sea areas near the shore, transform it to heat energy and store in hot water and cold water thermal energy storages. These storages will permit continuous energy production using the equipment of geothermal power plants. The travelling energy collector will be implemented as a catamaran with sails that include a multitude of small wind turbines. The solar concentrators will be placed on the deck of the catamaran. The catamaran will contain a hot water tank and a cold water tank to transport the heat energy to the power plant. It is necessary to make a large number of travelling energy collectors for one power plant. For this reason the catamaran must have an autonomous control system that will allow operation without human interaction.

\section{Acknowledgment}

This work was supported partially by projects CONACYT50231, PAPIIT IN110510-3, PAPIIT IN119610 and the project ICyTDF 330/2009.

\section{References}

[1] K. Rafferty, Geothermal power generation. A primer on low temperature, small-scale applications, http://geoheat.oit.edu/pdf/powergen.pdf.

[2] Y.Terao, K. Watanabe, M. Wakita, A feasibility study of an ocean power plant using a mega yacht system, Proceedings of the Second International Conference on Marine Research and Transportation, 2007, pp. 55-62.

[3] Kussul E., Baidyk T., Lara F., Saniger J., Bruce N., Estrada C., Micro facet solar concentrador, International Journal of Sustainable Energy, 2008, Vol.27, Issue 2, pp.6171.

[4] Kussul E., Baidyk T., Makeyev O., Lara-Rosano F., Saniger J.M., Bruce N., Flat facet parabolic solar concentrator, The 2nd WSEAS/IASME International Conference on Renewable Energy Sources (RES-08)-2008, October 26-28, 2008, Corfu, Greece, pp.4651. 